\title{
Breakfast eating and overweight in a pre-school population: is there a link?
}

\author{
Lise Dubois*, Manon Girard and Monique Potvin Kent \\ Department of Epidemiology and Community Medicine, Faculty of Medicine, Institute of Population Health, \\ University of Ottawa, 1 Stewart Street Office 303, Ottawa, Ontario, Canada, K1N 6N5
}

Submitted 12 April 2005: Accepted 10 August 2005

\begin{abstract}
Objectives: To analyse the socio-economic factors related to breakfast eating, the association between breakfast eating and overweight, and to gain a more thorough understanding of the relationship between these two elements in a population-based cohort of 4.5-year-old children. We hypothesised that a relationship could be observed between breakfast skipping and overweight independently of socioeconomic factors such as ethnicity, maternal education, single parenting and family income.

Design: A population-based study whereby standardised nutritional interviews were conducted with each child's parent. The children's height and weight were taken by a trained nutritionist and parents were asked about their child's breakfast eating.

Setting: The analyses were performed using data from the Québec Longitudinal Study of Child Development (1998-2002), conducted by Santé Québec (Canada).

Subjects: Subjects were 1549 children between the ages of 44 and 56 months, with a mean age of 49 months.

Results: Almost a tenth (9.8\%) of the children did not eat breakfast every day. A greater proportion of children with immigrant mothers (19.4\% vs. $8.3 \%$ from non-immigrant mothers), with mothers with no high school diploma (17.5\% vs. $<10 \%$ for higher educated mothers) and from low-income families (15\% for income of $\$ 39999$ or less vs. $5-10 \%$ for better income) did not eat breakfast every day. Not eating breakfast every day nearly doubled the odds (odds ratio $=1.9,95 \%$ confidence interval 1.2-3.2) of being overweight at 4.5 years when mother's immigrant status, household income and number of overweight/obese parents were part of the analysis.

Conclusion: Although our results require replication before public policy changes can be advocated, encouraging breakfast consumption among pre-school children is probably warranted and targeting families of low socio-economic status could potentially help in the prevention of childhood obesity.
\end{abstract}

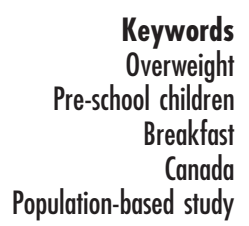

Obesity is currently recognised as a risk factor for many chronic diseases including cardiovascular disease, type 2 diabetes, stroke and cancer $^{1}$, and is associated with morbidity rates at least as high as poverty, smoking and excessive drinking ${ }^{2}$.

Childhood obesity is of particular concern since rates worldwide have been increasing at alarming levels. In the USA, overweight among children aged 6-11 years more than doubled between 1980 and 2000 and tripled among adolescents $^{3}$. In Canada, the number of children suffering from overweight and obesity has tripled among boys and doubled among girls in the last two decades ${ }^{4}$. According to the National Health and Nutrition Examination Study (NHANES 1999-2002), 22.6\% of pre-school children are at risk for overweight and $10.3 \%$ are overweight in the USA ${ }^{5}$, while $8.9 \%$ are overweight in the province of Québec, Canada $^{6}$. This increase in the rate of childhood obesity is particularly worrisome given the evidence that overweight children and adolescents are more likely to suffer from overweight and obesity as adults ${ }^{7}$ and be more severely obese as adults ${ }^{8}$.

Breakfast skipping has been associated with overweight $^{9,10}$ and specifically with higher body mass index (BMI) in adolescents ${ }^{11}$. School-age children who skip breakfast tend to be fatter than those who eat it ${ }^{12}$, and overweight and obese children have been found to skip breakfast more frequently than their normal-weight peers ${ }^{13}$. However, some research with children has not reported a link between breakfast skipping and overweight $^{14,15}$. Such inconsistencies in the literature point to a need for further research.

Since most studies have shown an association between skipping breakfast and obesity in different populations, the current trends in breakfast eating among children are 
troubling. A US analysis undertaken in 1991 of children aged 1 to 18 years indicated that breakfast eating has declined by approximately $5 \%$ in pre-school children and by $9 \%$ in $8-10$-year-olds from 1965 levels. The decline was greatest for adolescents, where consumption dropped by $13-20 \%{ }^{10}$. Currently it is estimated that $8 \%$ of $6-11$-yearolds and $22-25 \%$ of $12-19$-year-olds skip breakfast in the $\mathrm{USA}^{16}$. Similar rates of breakfast skipping have been described in the $\mathrm{UK}^{17}$ and Canada ${ }^{18}$ among populations of children. As is the case for obesity, breakfast eating in children and adolescents has been associated with various socio-economic factors including age, sex, socio-economic status ${ }^{19}$, race, parental education, income and school attendance $^{10}$.

Few studies have examined breakfast eating specifically with a pre-school population. Furthermore, the relationship between breakfast eating and obesity in this age group has not been explored to date and existing studies with older children and adolescents remain inconclusive. For this reason, we analysed the association between breakfast eating and overweight with a population of preschool children. We hypothesised that a relationship would be observed between breakfast skipping and overweight independently of socio-economic factors such as ethnicity, maternal education, single parenting and family income.

\section{Methods}

The focus of the present study was the analysis of socioeconomic factors related to breakfast eating in a preschool population. This examination was undertaken to determine if breakfast eating had an independent role in overweight when other social and parental variables were taken into account. The association between breakfast eating and overweight in a pre-school population was also explored. In addition, the factors related to daily breakfast eating and overweight were examined in a multivariate analysis to get a better understanding of the relationship between these two elements in a population-based cohort of 4.5-year-old children from Québec (Canada).

The analyses were performed using data from the Québec Longitudinal Study of Child Development (19982002) (QLSCD), conducted by Santé Québec, a division of the Institut de la Statistique du Québec in Canada ${ }^{6,20}$. This study, funded in part by the Ministère de la Santé et des Services sociaux du Québec, analysed the role of familial and social factors on children's health and on cognitive and behavioural development. It followed a representative sample $(n=2103)$ of children born in 1998 in the province of Québec (total population over 7 million, with approximately 70000 newborns per year). The representative sample was chosen by a random selection of children born throughout the year in each public health geographic area of the province, therefore minimising the seasonality effect and ensuring geographic representation. The children were first seen at 5 months (gestational age) and subsequently at 1-year intervals. Twins and children with major diseases or handicaps at birth were not part of the study.

Each testing point involved standardised, questionnairebased, face-to-face interviews with the children's mothers and fathers. Interviews were conducted with the caregiver deemed the most knowledgeable of the child, generally the mother. The age of the children in the present study varied from 44 to 56 months with a mean age of 49 months.

Of the 2103 babies at the first data collection point, 1944 remained at $4-5$ years in 2002 . Of this group, a sub-sample of 1549 was selected to take part in the nutrition study. This component included a 24-hour dietary recall, the breakfast eating questionnaire and measurement of the children's height and weight. Children's height and weight were measured at home by a trained nutritionist following a standardised protocol. Children's weight was then analysed using body mass index (BMI), calculated as weight $(\mathrm{kg}) /\left[\right.$ height $(\mathrm{m})^{2}$ ]. Overweight was first defined as having BMI at or above the 95th percentile on the US Centers for Disease Control and Prevention (CDC) growth charts (2000) that are sex- and age-specific ${ }^{21}$. Next, overweight/obesity was defined according to Cole's criteria $^{22}$. Breakfast eating was measured by a standardised questionnaire ${ }^{23}$ which asked parents if their child was eating breakfast every day (yes every morning; regularly but not every day; only on occasion; never). For the analysis, the answers were regrouped as 'eating breakfast every day' (for yes every morning) versus 'not eating breakfast every day' (for the other answers). We verified the accuracy of the answer to this question with the data from the 24-hour recall. The second 24-hour recall was administered to half of the sample so that the original recall data could be adjusted for intra-variability to ensure representativeness of usual food consumption. Whenever there were inconsistencies between the original 24-hour dietary recall and the breakfast eating question ( $2 \%$ of the children), the second 24-hour recall, when available, was used to classify the children as breakfast skippers or eaters. Except for one case, children who did not have breakfast on the first 24-hour recall did not have breakfast either on the second one. Data were weighted by a factor based on the inverse of the selection probability, the probability of non-response and the post-stratification and attrition rates, to ensure that the data were longitudinally representative of the babies born in 1998 in the population ${ }^{24}$. Preliminary analyses indicated that the 1549 children participating in the nutrition study were representative not only of the babies born in 1998 but also of the same-aged children (at 4.5 years) in the population. Statistical analyses were based on individuals with no missing values for any of the studied variables. Of the 1549 babies, 1520 (98\% of the sample) were part of the analyses. We analysed the impact 
of missing data by conducting with-and-without analyses. Missing data were excluded from the analyses since they had no impact on the results.

Different factors could be related to children's breakfast eating and overweight status. From the literature review and the variables available in the study, the factors selected are presented in Table 1, along with their proportion for our population of pre-school children. Family type (single-parent family or not), household annual income $(<\$ 20000 ; \quad \$ 20000-39999$; $\$ 40000-59999 ; \geq \$ 60000$ ), mothers' education (no high school diploma; high school diploma; college diploma; university degree) and immigrant status (immigrant or not) were part of the analysis. Other variables that were included were the mother's and father's BMI (from reported weight and height), the number of overweight/ obese parents, child's day-care attendance (not in day-care or being taken care of at home; being taken care of at someone else's home; in a day-care centre) and maternal perception of the child's eating habits (excellent; very good; good/average/bad).

Statistical analyses were done with SAS version 8.2 (SAS Institute, Cary, NC, USA). All variables were treated as categorical variables and all analyses were adjusted for children's age. Preliminary associations between the independent variables and weights were verified through a chi-square test on contingency tables. Significant independent variables were included in multivariate analyses. Adjustments for potential confounders and odds ratios estimates, as well as their confidence intervals, were made with logistic regressions. Weighted data were used in the analysis and the significance level was set at 5\%.

To get a better understanding of the relationship between breakfast eating and overweight, first an identification of the factors related to breakfast eating was conducted and then an analysis of their impact on the relationship of breakfast eating and overweight was carried out. These analyses were carried out twice, using

Table 1 Proportion (\%) of children not eating breakfast every day and proportion (\%) of overweight children by different characteristics

\begin{tabular}{|c|c|c|c|c|c|}
\hline Characteristic & Category & $\%$ & $\begin{array}{l}\text { Not eating } \\
\text { breakfast } \\
\text { every day }\end{array}$ & $\begin{array}{l}\text { Overweight } \\
\text { childrent }\end{array}$ & $\begin{array}{l}\text { Overweight/obese } \\
\text { children } \ddagger\end{array}$ \\
\hline Total & & & 9.8 & 8.8 & 14.3 \\
\hline \multirow{2}{*}{ Child's sex } & Girl & 49.0 & 8.2 & 7.3 & 14.4 \\
\hline & Boy & 51.0 & 11.2 & 10.3 & 14.2 \\
\hline \multirow{2}{*}{ Mother's immigrant status } & Non-immigrant & 86.4 & $8.3^{*}$ & $8.0^{*}$ & 13.5 \\
\hline & Immigrant & 13.6 & 19.4 & 13.3 & 18.8 \\
\hline \multirow[t]{4}{*}{ Mother's education } & No high school diploma & 15.7 & $17.5^{\star}$ & 10.8 & 14.2 \\
\hline & High school diploma & 22.0 & 9.8 & 10.3 & 17.4 \\
\hline & College diploma & 35.1 & 7.9 & 7.4 & 11.6 \\
\hline & University degree & 27.2 & 7.6 & 8.6 & 15.3 \\
\hline \multirow[t]{4}{*}{ Mother's BMI $\left(\mathrm{kg} \mathrm{m}^{-2}\right)$} & $<18.5$ & 6.7 & 11.1 & $4.2^{*}$ & $7.9^{*}$ \\
\hline & $18.5-24$ & 65.0 & 8.6 & 6.8 & 11.5 \\
\hline & $25-29$ & 18.9 & 10.9 & 11.7 & 19.9 \\
\hline & $\geq 30$ & 9.4 & 14.8 & 20.2 & 26.4 \\
\hline \multirow{4}{*}{ Father's BMI $\left(\mathrm{kg} \mathrm{m}^{-2}\right)$} & $<18.5$ & 0.5 & 21.7 & $0.0^{*}$ & $0.0^{*}$ \\
\hline & $18.5-24$ & 42.9 & 10.4 & 5.6 & 9.3 \\
\hline & $25-29$ & 44.6 & 8.6 & 9.5 & 15.9 \\
\hline & $\geq 30$ & 12.0 & 7.4 & 15.1 & 22.9 \\
\hline \multirow[t]{3}{*}{ Number of overweight/obese parents } & 0 parent & 37.5 & 10.6 & $5.0^{*}$ & $9.3^{*}$ \\
\hline & 1 parent & 47.0 & 8.7 & 9.3 & 14.4 \\
\hline & 2 parents & 15.5 & 11.4 & 16.3 & 26.2 \\
\hline \multirow{2}{*}{ Single-parenting } & No & 85.6 & 9.8 & 8.4 & 13.4 \\
\hline & Yes & 14.4 & 9.3 & 11.4 & 19.5 \\
\hline \multirow[t]{4}{*}{ Household annual income } & $<\$ 20000$ & 10.1 & $14.9^{*}$ & 12.8 & 22.6 \\
\hline & $\$ 20000-39999$ & 20.7 & 14.9 & 11.8 & 15.8 \\
\hline & $\$ 40000-59999$ & 26.4 & 10.4 & 7.7 & 12.4 \\
\hline & $\geq \$ 60000$ & 42.8 & 5.8 & 7.2 & 12.8 \\
\hline \multirow[t]{3}{*}{ Day-care attendance } & Not in day-care & 30.7 & 9.3 & 7.2 & 12.6 \\
\hline & $\begin{array}{l}\text { In day-care at someone } \\
\text { else's home }\end{array}$ & 35.1 & 8.5 & 8.8 & 14.4 \\
\hline & In a day-care centre & 34.2 & 11.6 & 10.4 & 15.7 \\
\hline \multirow{3}{*}{$\begin{array}{l}\text { Mother's perception of } \\
\text { child's eating habits }\end{array}$} & Excellent & 14.8 & $2.8^{*}$ & 11.1 & 14.6 \\
\hline & Very good & 46.8 & 8.0 & 7.7 & 13.6 \\
\hline & Good/average/bad & 38.4 & 14.8 & 9.4 & 14.9 \\
\hline \multirow[t]{2}{*}{ Breakfast eating } & Not eating breakfast every day & 7.5 & - & $17.1^{*}$ & $24.5^{\star}$ \\
\hline & Eating breakfast every day & 92.5 & - & 8.1 & 13.4 \\
\hline
\end{tabular}

BMI - body mass index.

* Statistically significant association between the characteristic and the dependant variable (chi-square $P \leq 0.05$ ).

$\dagger$ Children with a BMI at or over the 95th percentile on the 2000 Centers for Disease Control and Prevention growth charts ${ }^{21}$ (age- and sex-specific curves). $\ddagger$ Overweight/obese based on Cole et al.'s criteria ${ }^{22}$. 
both definitions of overweight/obese. In the first analysis overweight was defined as being at the 95th percentile or over on the 2000 CDC growth charts, while in the second analysis, overweight/obese was defined by Cole et al.'s criteria.

\section{Results}

Table 1 presents the proportion of children not eating breakfast every day and the proportion of overweight children by the studied factors. Almost a tenth (9.8\%) of the children did not eat breakfast every day. In addition, a lower proportion of children not eating breakfast every day were perceived by their mother as having excellent or very good eating habits, in comparison with children perceived to have only good, average or bad eating habits.

Around $8.8 \%$ of the 4.5-year-old children were overweight using the 2000 CDC growth charts at the 95th percentile or over, and $14.3 \%$ were overweight or obese using Cole's criteria. Regardless of the definition of overweight, children with mothers and/or fathers with a high BMI were more likely to be overweight. In comparison with children with no overweight/obese parent, twice as many children with one overweight/obese parent were overweight and three times as many children with two overweight/obese parents were overweight.

Not eating breakfast every day was associated with overweight. Twice as many children not eating breakfast every day were overweight at 4.5 years, in comparison with children eating breakfast every day.

The factors contributing the most to breakfast eating amongst the significant ones from the univariate analysis (Table 1) were mother's education, her immigrant status and household income (Table 2). In the multivariate analysis, the odds for not eating breakfast every day almost tripled for children with immigrant mothers, compared with children with non-immigrant mothers, and almost doubled for children with mothers with no high school diploma, compared with children whose mothers had a university degree. Being in a family with low household income doubled the odds for not eating breakfast every day in comparison to having a high income. These results are important as univariate analysis indicated that breakfast eating was related to overweight at 4.5 years.

The relationship between eating breakfast and overweight was then studied using multivariate analysis taking into consideration the other related variables such as the child's sex, parental overweight/obesity, mother's education and immigrant status, and household income (Table 2). Using the 2000 CDC growth chart percentiles, not eating breakfast every day almost doubled the odds of being overweight at 4.5 years when child's sex, mother's immigrant status and number of overweight/obese parents were part of the analysis. Mother's education and family income were not related to overweight in the multivariate analysis. When all of these analyses were repeated using Cole's definition of overweight/obese,

Table 2 Adjusted $\dagger$ odds ratios (OR) and 95\% confidence interval (Cl) for children not eating breakfast every day and for overweight children by different characteristics

\begin{tabular}{|c|c|c|c|c|}
\hline \multirow[b]{2}{*}{ Characteristic } & \multirow[b]{2}{*}{ Category } & \multicolumn{3}{|c|}{ OR (95\% Cl) } \\
\hline & & $\begin{array}{l}\text { Not eating breakfast } \\
\text { every day }\end{array}$ & Overweight children $\ddagger$ & $\begin{array}{l}\text { Overweight/obese } \\
\text { children§ }\end{array}$ \\
\hline \multirow[t]{2}{*}{ Sex } & Female\|l & - & 1.000 & 1.000 \\
\hline & Male & - & $1.501(1.031-2.186)^{\star}$ & $0.984(0.729-1.328)$ \\
\hline \multirow{2}{*}{$\begin{array}{l}\text { Mother's immigrant } \\
\text { status }\end{array}$} & Non-immigrant\| & 1.000 & 1.000 & 1.000 \\
\hline & Immigrant & $2.664(1.744-4.070)^{\star}$ & $1.692(1.029-2.782)^{\star}$ & $1.511(1.003-2.300)^{\star}$ \\
\hline \multirow[t]{4}{*}{ Mother's education } & No high school diploma & $1.880(1.059-3.336)^{\star}$ & $0.946(0.504-1.773)$ & $0.665(0.391-1.130)$ \\
\hline & High school diploma & $1.021(0.582-1.791)$ & $0.938(0.540-1.629)$ & $0.903(0.582-1.402)$ \\
\hline & College diploma & 0.870 (0.524-1.443) & $0.689(0.416-1.140)$ & $0.612(0.409-0.915)$ \\
\hline & University degree\| & 1.000 & 1.000 & 1.000 \\
\hline \multirow{3}{*}{$\begin{array}{l}\text { Number of overweight/ } \\
\text { obese parents }\end{array}$} & 0 parentl\| & - & 1.000 & 1.000 \\
\hline & 1 parent & - & $2.230(1.398-3.557)^{\star}$ & $1.821(1.266-2.620)^{*}$ \\
\hline & 2 parents & - & $4.031(2.356-6.898)^{\star}$ & $3.864(2.525-5.912)^{*}$ \\
\hline \multirow{4}{*}{$\begin{array}{l}\text { Household annual } \\
\text { income }\end{array}$} & $<\$ 20000$ & $2.187(1.174-4.075)^{\star}$ & $1.748(0.910-3.358)$ & $2.178(1.298-3.654)^{\star}$ \\
\hline & $\$ 20000-39999$ & $2.110(1.262-3.529)^{\star}$ & $1.465(0.862-2.490)$ & $1.254(0.808-1.946)$ \\
\hline & $\$ 40000-59999$ & $1.579(0.967-2.577)$ & $0.997(0.605-1.644)$ & $0.967(0.647-1.446)$ \\
\hline & $\geq \$ 60000 \|$ & 1.000 & 1.000 & 1.000 \\
\hline \multirow[t]{2}{*}{ Breakfast eating } & $\begin{array}{l}\text { Not eating breakfast } \\
\text { every day }\end{array}$ & - & $1.925(1.161-3.194)^{\star}$ & $1.676(1.078-2.606)^{\star}$ \\
\hline & $\begin{array}{l}\text { Eating breakfast } \\
\text { every dayll }\end{array}$ & - & 1.000 & 1.000 \\
\hline
\end{tabular}

* Significantly different from the reference category $(P \leq 0.05)$.

† Adjusted for all of the included characteristics.

- indicates that characteristic was not included for this dependent variable.

$\mp$ Children with a BMI at or over the 95th percentile on the 2000 Centers for Disease Control and Prevention growth charts ${ }^{21}$ (age- and sex-specific curves).

$\S$ Overweight/obese based on Cole et al.'s criteria ${ }^{22}$.

I Crude odds (for overweight children) for children not eating breakfast every day is 2.335 (95\% Cl 1.382-3.946).

|| Reference category. 
similar results were found except with regard to sex and socio-economic status.

\section{Discussion}

According to our analysis, 9.8\% of the population of 4.5-year-olds in Québec are not eating breakfast every day. This rate concurs with that found in other representative pre-school populations in the $\mathrm{USA}^{10}$ but is higher than that found by Hooper and Evers, who described a non-representative sample of 305 4-year-olds in Ontario (Canada) and a breakfast skipping rate of $4.9 \%{ }^{25}$. The number of pre-school children in our population who do not eat breakfast every day is low compared with older populations of children that have been examined elsewhere or even in Québec ${ }^{23}$. However, this higher rate of breakfast skipping with older children is not surprising given that most research shows increasing levels of breakfast skipping as children age ${ }^{10}$.

This rate of breakfast skipping at the pre-school level is troubling on many fronts. In the first instance, research has pointed to the fact that those who skip breakfast lag behind from a nutritional standpoint. Basiotis et $a l^{26}$ concluded that overall diet quality of 6-18-year-olds was improved with breakfast eating. In addition to their poorer nutritional status, there is increasing evidence that, particularly for at-risk children, those who skip breakfast perform more poorly at learning and cognitive tasks ${ }^{27}$. Lastly, skipping breakfast is associated with significantly greater rates of overweight in pre-school children as suggested in our study. Indeed, in our population of 4.5-year-olds, $17 \%$ of those who did not eat breakfast every day were overweight compared with only $8 \%$ of those who ate breakfast every day, using the 2000 CDC growth charts. When child's sex, mother's immigrant status and number of overweight or obese parents were taken into account, not eating breakfast every day almost doubled the odds of being overweight at 4.5 years in our study.

This positive relationship between breakfast skipping and overweight in our pre-school population has been observed in populations of older school children ${ }^{13,28,29}$ and in adolescents ${ }^{9-11}$. Although the preponderance of evidence shows an association between breakfast skipping and overweight for children and adolescents, Nicklas et al. ${ }^{14}$ failed to find a relationship between meal patterns including breakfast skipping and overweight in their sample of 1584 children aged 10 years from Bogalusa, Louisiana. Also, a study conducted with a sample of innercity African Americans in grades 2-5 did not find a relationship between breakfast skipping and obesity ${ }^{15}$. Although both these studies were conducted with large sample sizes, neither was done using a representative sample of populations and, as such, their results may not be generalisable to all American children.
Our research did reveal multiple social and parental variables that were associated with not eating breakfast every day, including the mother's immigrant status, her education and the family's income level. Higher family income has also been associated with greater breakfast consumption in a population-based sample of 1-14-yearolds in the $\mathrm{USA}^{10}$, with 6-19-year-olds in Australia ${ }^{30}$ and with Dutch adults ${ }^{31}$. An Australian study with adolescents, however, found no differences in breakfast skipping according to socio-economic status or education of the parents $^{32}$. Instead, that study concluded that breakfast skipping was a personal choice. It could be that the relationship between socio-economic status and breakfast eating differs with different populations, that Shaw's study $^{33}$ was not based on a representative sample of the population, or that breakfast skipping may be a personal choice at adolescence but not yet in the pre-school years when parents exert more control on the child's diet.

We found no sex differences in breakfast eating in our population of 4.5-year-olds. Sex differences in breakfast consumption seem to become more predominant as children age. Shaw ${ }^{32}$, Siega-Riz et al. ${ }^{10}$ and Hackett et al. ${ }^{17}$ all reported that adolescent girls skipped breakfast more frequently than similarly aged boys. Sex differences in breakfast eating by older female children may be the result of societal pressure and expectations which do not exist at the pre-school level.

No association between single parenting and breakfast eating was found in our study. This lack of association has also been described in populations of second and fifth graders in the USA ${ }^{29}$. However, another study with children aged 6-12 years who were representative of children in New York State concluded that those who skipped breakfast were almost twice as likely as breakfast eaters to be overweight only if they came from a twoparent family ${ }^{12}$. Given these diverging results, further research is needed to clarify the impact of single-parent families on breakfast eating.

The mother as immigrant variable, although significantly related to breakfast eating, presents some interpretative challenges because of the small numbers involved. Our research revealed that no other population-based studies have examined this potential relationship. It is important to note that immigrant status, low maternal education and low household income are related factors at the population level. However, according to our multivariate analysis, they each played an independent role in the relationship between breakfast skipping and overweight in the pre-school years.

Methodologically, the strengths of our study include a representative population-based birth cohort. Our results are thus generalisable to our population. Our strengths also include using trained nutritionists to measure height and weight as opposed to relying on self-report measures from the child's parent. Finally, although we presented results based on a measure of overweight that was defined 
as BMI at or above the 95th percentile on the 2000 CDC growth charts ${ }^{21}$, we also ran our analyses with Cole et al.'s measurement of childhood overweight/obese ${ }^{22}$ which relates the prevalence of overweight and obesity at age 18 years for both males and females to earlier ages. Both analyses were run since there is debate as to which measure best assesses childhood overweight/obesity. However, regardless of the measure used, our results did not differ.

Drawbacks of our study included that the parent's height and weight were self-reported rather than measured, which would have given us more precision in our number of parents overweight/obese variable. Different validation studies of adult self-report data indicate that weight is generally underestimated and height is generally overestimated, resulting in an underestimation of BMI values at the population level ${ }^{33-35}$. We can therefore assume that the observed relationship would have been even stronger with measured values. Other drawbacks to our study included failing to examine the role of other important confounders including the daily dietary intake and physical activity level of breakfast eating compared with breakfast skipping preschool children. Since the scope of this article had to be limited, the nutritional differences between breakfast eaters and skippers will be analysed at a later time and presented in a subsequent paper.

In summary, even if Canada is a wealthy country with a broad range of social programmes, a significant number of pre-school children skip breakfast. Our study is the first, as far as we are aware, to examine the link between breakfast skipping and overweight with a pre-school population. However, despite the fact that our research needs replication, our results seem to point to the development of public policy that stresses the importance of breakfast eating. This message might be targeted to families of low socio-economic status and might also be aimed at parents with older children, particularly given the worrisome trend of increasing rates of breakfast skipping through the adolescent years. Encouraging breakfast consumption on a population basis is a measure that can be easily implemented and has the potential to aid in the prevention of childhood obesity.

\section{Acknowledgements}

L.D.'s research work is supported by the Canada Research Chair Program. This study has been partly financed by the Canadian Institute of Health Information, Canadian Population Health Initiative, and by the Canadian Institute of Health Research.

\section{References}

1 World Health Organization (WHO). Controlling the global obesity epidemic [online], 2003. Available at http://www.who.int/nutrition/topics/obesity.en/
2 Sturm R, Wells KB. Does obesity contribute as much to morbidity as poverty or smoking? Public Health 2001; 115: 229-35.

3 Ogden CL, Flegal KM, Carroll MD, Johnson CL. Prevalence and trends in overweight among US schoolchildren and adolescents, 1999-2000. Journal of the American Medical Association 2002; 288: 1728-32.

4 Statistics Canada. National longitudinal survey of children and youth: childhood obesity. The Daily, 18 October 2002.

5 Hedley AA, Ogden CL, Johnson CL, Carroll MD, Curtin LR, Flegal KM. Prevalence of overweight and obesity among US children, adolescents and adults, 1999-2002. Journal of the American Medical Association 2004; 291: 2847-50.

6 Dubois L, Girard M. L'alimentation des enfants d'âge préscolaire. In: Étude longitudinale du développement des enfants du Québec (ÉLDEQ 1998-2002). Québec: Institut de la Statistique du Québec, 2002.

7 Ferraro KF, Thorpe RJ Jr, Wilkinson JA. The life course of severe obesity: does childhood overweight matter? Journal of Gerontology 2003; 58B: S110-9.

8 Freedman DS, Khan LK, Dietz WH, Srinivasan SR, Berenson GS. Relationship of childhood obesity to coronary heart disease risk factors in adulthood: the Bogalusa Heart Study. Pediatrics 2001; 108: 712-8.

9 Berkey CS, Rockett HRH, Gillman MW, Field AE, Colditz GA. Longitudinal study of skipping breakfast and weight change in adolescents. International Journal of Obesity and Related Metabolic Disorders 2003; 27: 1258-66.

10 Siega-Riz A-M, Popkin B, Carson T. Trends in breakfast consumption for children in the United States from 19651991. American Journal of Clinical Nutrition 1998; 67: $748 \mathrm{~S}-56 \mathrm{~S}$.

11 Keski-Rahkonene A, Kaprio J, Rissanen A, Virkkunen M, Rose RJ. Breakfast skipping and health-compromising behaviors in adolescents and adults. European Journal of Clinical Nutrition 2003; 57: 842-53.

12 Wolfe WS, Campbell CC, Frongillo EA, Haas JD, Melnik TA. Overweight schoolchildren in New York: prevalence and characteristics. American Journal of Public Health 1994; 84: 807-13.

13 Ortega RM, Requejo AM, Lopez-Sobaler AM, Quintas ME, Andres P, Redondo MR, et al. Difference in the breakfast habits of overweight/obese and normal weight schoolchildren. International Journal for Vitamin and Nutrition Research 1998; 68: 125-32.

14 Nicklas TA, Morales M, Linares A, Yang SJ, Baranowski T, De Moor C, et al. Children's meal patterns have changed over a 21-year period: The Bogalusa Heart Study. Journal of the American Dietetic Association 2004; 104: 753-61.

15 Sampson AE, Dixit S, Meyers AF, Houser R Jr. The nutritional impact of breakfast consumption on the diets of inner-city African-American elementary school children. Journal of the National Medical Association 1995; 87: 195-202.

16 United States Department of Agriculture (USDA). Continuing Survey of Food Intakes by Individuals 1994-96. Washington, DC: USDA, 1998.

17 Hackett AF, Gibbon M, Sratton G, Hamill L. Dietary intake of 9-10-year-old and 11-12-year-old children in Liverpool. Public Health Nutrition 2002; 5: 449-55.

18 McIntyre L. A survey of breakfast skipping and inadequate breakfast-eating among young schoolchildren. Canadian Journal of Public Health 1993; 84: 410-4.

19 Aranceta J, Serra-Majem L, Ribas L. Pérez-Rodrigo. Breakfast consumption in Spanish children and young people. Public Health Nutrition 2001; 4: 1439-44.

20 Dubois L, Bédard B, Girard M, Beauchesne É. L'alimentation. Les nourrissons de 5 mois. In: Étude longitudinale $d u$ développement des enfants du Québec (ÉLDEQ 1998-2002). Québec: Institut de la Statistique du Québec, 2000. 
21 National Center for Health Statistics, Centers for Disease Control and Prevention. CDC growth charts [online], 2000. Available at http://www.cdc.gov/growthcharts/

22 Cole TJ, Bellisi C, Flegal KM, Dietz WH. Establishing a standard definition for child overweight and obesity worldwide: international survey. British Medical Journal 2000; 320: 1240-3.

23 Institut de la Statistique du Québec. Enquête sociale et de santé auprès des enfants et des adolescents québécois. Québec: Institut de la Statistique du Québec, 1999.

24 Cox GG, Cohen SB. Methodological Issues for Health Care Surveys. New York: Marcel Dekker, 1985.

25 Hooper M, Evers S. What do Ontario children eat for breakfast? Food group, energy and macronutrient intake. Canadian Journal of Dietetic Practice and Research 2003; 64: $28-30$.

26 Basiotis PP, Lino M, Anand RS. Eating breakfast greatly improves schoolchildren's diet quality. Family Economics and Nutrition Review 1999; 12: 81-4.

27 Pollitt E, Matthew R. Breakfast and cognition: an integrative summary. American Journal of Clinical Nutrition 1998; 67(Suppl.): 804S-13S.

28 Vignerová J, Bláha P, Ošancová K, Roth Z. Social inequality and obesity in Czech school children. Economics and Human Biology 2004; 2: 107-18.

29 Wolfe WS, Campbell CC. Food pattern, diet quality, and related characteristics of schoolchildren in New York State.
Journal of the American Dietetic Association 1993; 93 $1280-4$.

30 O'Dea JA, Caputi P. Association between socio-economic status, weight, age and gender, and the body image and weight control practices of 6-to 19-year-old children and adolescents. Health Education Research 2001; 16: 521-32.

31 Hulshof KFAM, Brussaard JH, Kruizinga AG, Telman J, Löwik MRH. Socio-economic status, dietary intake and 10 y trends: the Dutch National Food Consumption Survey. European Journal of Clinical Nutrition 2003; 57: 128-37.

32 Shaw ME. Adolescent breakfast skipping: an Australian study. Adolescence 1998; 33: 851-61.

33 Nawaz H, Chan W, Abdulrahman M, Larson D, Katz DL. Selfreported weight and height: implications for obesity research. American Journal of Preventive Medicine 2001; 20: $294-8$

34 Gunnell D, Berney L, Holland P, Maynard M, Blane D, Frankel S, et al. How accurately are height, weight and leg length reported by the elderly, and how closely are they related to measurements recorded in childhood? International Journal of Epidemiology 2000; 29: 456-64.

35 Bostrom G, Diderichsen F. Socioeconomic differentials in misclassification of height, weight and body mass index based on questionnaire data. International Journal of Epidemiology 1997; 26: 860-6. 